\title{
TERRITÓRIOS, MOBILIDADES E ESTÉTICAS INSURGENTES. REFLETINDO SOBRE PRÁTICAS E REPRESENTAÇõES COLETIVAS DE REALIZADORES VISUAIS NAS METRÓPOLES
} CONTEMPORÂNEAS

Guilhermo Aderaldo ${ }^{1}$

Universidade de São Paulo, São Paulo, Brasil

\begin{abstract}
Partindo de reflexóes construídas no decorrer de duas pesquisas etnográficas recentes, este artigo visa trazer alguns apontamentos mais sistemáticos sobre a forma pela qual a popularização do acesso a ferramentas de produção visuall audiovisual tem possibilitado a construção de novas modalidades de associativismo e engajamento politico nas metrópoles latino americanas contemporâneas, sobretudo, por parte de jovens trabalhadores precários, nas chamadas "profissões criativas". Para isso, examino experiências de "ativismo cultural" ou "arte ativismo", protagonizadas por três coletivos das cidades de São Paulo e Rio de Janeiro, buscando compreender o modo pelo qual os mesmos interpelam criticamente as lógicas hegemônicas responsáveis pela conformação de modelos urbanisticos profundamente excludentes.
\end{abstract}

Palavras chave: cidade, associativismo, coletivos artístico-ativistas, intervenções visuais urbanas, sociabilidade

1 Doutor em Antropologia Social pela Universidade de São Paulo (USP). É autor de Reinventando a cidade: Uma etnografia das lutas simbólicas entre coletivos culturais vídeo-ativistas nas "periferias" de São Paulo (Annablume/ Fapesp, 2017) e pesquisador em Pós-doutorado (FAPESP) vinculado aos departamentos de antropologia da Universidade de São Paulo (USP) e da Universidad de Buenos Aires (UBA).E-mail: guiade@ymail.com. O presente artigo é baseado nas comunicações que apresentei no VI Congresso da Associação Portuguesa de Antropologia (APA), realizado na cidade de Coimbra, em junho de 2016 e na 30 Reunião Brasileira de Antropologia, ocorrida na cidade de João Pessoa, em agosto de 2016. Agradeço especialmente à Fundação de Amparo à Pesquisa do Estado de São Paulo (FAPESP), pelo financiamento das pesquisas de doutorado (Processo No 2009/50153-2) e pós-doutorado (Processo No 2014/04243-8) que dão lugar às reflexões contidas no texto. Lembro ainda que as opiniões e conclusões ou recomendações expressas neste artigo são de responsabilidade do autor e não necessariamente refletem a visão da FAPESP. 


\section{(...) é verdade que o mundo é o que vemos e que, contudo, preci- samos aprender a vê-lo (Ponty, 2014: 16).}

Reconhecidamente polifônicos (Canevacci, 2004; Campos, 2011a; 2011b) e pluriétnicos (Agier, 1999; 2011 [2009]; 2013), os espaços urbanos contemporâneos são, igualmente, caracterizados pela presença de uma visualidade específica a qual decorre, entre outras coisas, do contato entre percepções de mundo marcadas por experiências sociais profundamente diversas e assimétricas. Tal visualidade, há muito, se expressa por meio da presença de tags, graffitis, pichações, marcas publicitárias, entre outras expressões responsáveis por tingir as fronteiras que recortam a paisagem segregada das metrópoles.

Contudo, nos últimos anos, mediante o desenvolvimento e a popularização das tecnologias comunicativas, a disputa simbólica relacionada à produção de imagens nas e sobre as cidades parece ter alcançado um novo patamar; estimulando, inclusive, o desenvolvimento de formas renovadas de sociabilidade, associativismo e engajamento político por parte, sobretudo, de jovens que, apesar do perfil bastante heterogêneo, encontram-se similarmente interessados no aperfeiçoamento de dispositivos e modelos de manifestação pública voltados à expansão das possibilidades acerca do que é dizível e visível a respeito das desigualdades sociais urbanas ${ }^{2}$.

Tomando então, como plano de referência, esta complexa relação entre, por um lado, 1) a popularização do acesso às tecnologias comunicativas e, por outro, 2) as novas formas de sociabilidade urbana, a proposta deste artigo será a de - ainda que brevemente - perscrutar as ações e relações desenvolvidas por três experiências de "ativismo cultural" decorrer de duas pesquisas etnográficas recentes, realizadas nas cidades de São Paulo e Rio de Janeiro ${ }^{4}$.

Começo apresentando o caso da rede de comunicadores intitulada Coletivo de Vídeo Popular (CVP) para, em seguida, refletir, por meio de tópicos específicos, sobre algumas das práticas realizadas pelos coletivos Projetação e Imargem. Por fim, me encaminho para as considerações finais, onde buscarei sistematizar algumas reflexões a respeito das novas formas de

2 Sobre estas formas renovadas de socialização e de manifestação pública, vale também consultar a coletânea sobre a chamada "geração indignada", organizada por Feixa e Nofre (2013).

3 Nos últimos anos, termos como "artivismo", "ativismo cultural" e "ativismo artístico", ganharam forte repercussão pública. Conforme pondera Di Giovanni (2015b: 14), todas essas expressões buscam denunciar "experiências mal contidas pelas fronteiras convencionais que separam a 'política' da 'arte'". Todavia, a mesma autora, ao dialogar com o trabalho de Graeber (2007), alerta também para o fato de que a principal qualidade das intervenções ditas "criativas", no mundo contemporâneo, consiste na possibilidade das mesmas em deslocar continuamente as fronteiras acerca do que é considerado "estético" e daquilo que costuma ser pensado como "político", de modo que sejam capazes de retirar das autoridades "oficiais" o direito de definir tais enquadramentos. Assim, opto aqui por utilizar o termo "ativismo cultural" pelo fato de, a meu ver, o mesmo conservar a perspectiva da fronteira, normalmente manipulada pelos sujeitos pesquisados, ao contrario da noção de "artivismo", que supõe a abolição da mesma.

4 Refiro-me aqui, mais especificamente, às minhas pesquisas de doutorado e de pós-doutorado (atualmente em curso). 
intervenção estética e política que vem ganhando espaço nas grandes cidades globais e, mais especificamente, nas metrópoles latino americanas.

O objetivo será demonstrar como a possibilidade de reinventar a forma e o sentido de fenômenos sociais e espaciais, desencadeada pela posse de novos dispositivos de comunicação, tem contribuído para a "produção de localidades" (Appadurai, 2005 [1996]) políticas mais alargadas e complexas, decorrentes da engenharia imaginativa - sobretudo de jovens -, que consiste em relacionar lugares e populações marcados por profundos processos de desigualdade, em torno de elementos simbólicos comuns.

Espero, assim, contribuir para uma reflexão mais apurada sobre a importância alcançada pela manipulação de ferramentas visuais e comunicativas na luta por reconhecimento e direitos.

\section{Coletivo de Vídeo Popular (CVP)}

A primeira experiência a ser destacada, refere-a ao processo de formação e consolidação de uma rede de comunicadores populares chamada Coletivo de Vídeo Popular (também conhecida como "rede do vídeo popular" ou, simplesmente, pelo uso da sigla "CVP"), que acompanhei durante minha investigação de doutorado .

Esta rede - que teve como um de seus principais desafios, a tarefa de desenvolver um sistema autônomo de comunicação e trocas entre áreas e populações marginalizadas de São Paulo - formou-se no ano de 2007 a partir da iniciativa de um grupo de jovens realizadores, os quais

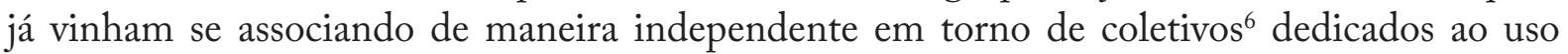
político de uma série de dispositivos de comunicação audiovisual (câmeras, telefones portáteis, computadores, projetores, etc.).

Boa parte desses realizadores havia aprendido a operar tais ferramentas comunicativas logo após passarem por diferentes oficinas e cursos voltados à chamada "educação audiovisual popular" (Cirello, 2010), os quais costumam ser ministrados, sobretudo, através de "projetos sociais" desenvolvidos por ONGs em áreas periféricas da capital paulista ${ }^{7}$.

$5 \quad$ A pesquisa foi realizada entre os anos de 2009 e 2013. Para mais detalhes, ver Aderaldo (2016; 2017).

6 Tais “coletivos" são, em linhas gerais, pequenos núcleos, geralmente sem formalização jurídica, constituídos por poucos integrantes (quase sempre vizinhos ou amigos) que, além de produzirem vídeos, também costumam atuar exibindo filmes próprios ou produzidos por outros coletivos em diversos espaços da cidade.

7 Na primeira década dos anos 2000, mediante o advento da tecnologia digital e o consequente barateamento e portabilidade dos meios de produção audiovisuais, diversas instituições assumiram a responsabilidade de formar, em cursos e oficinas voltados à produção de vídeos, populações ligadas a regiões periféricas em todo o Brasil, sob a justificativa de oferecer a oportunidade para que as mesmas pudessem construir "suas próprias representaçôes" a respeito dos ambientes sociais que as circundam, confrontando assim, as narrativas hegemônicas sobre o problema da desigualdade urbana. Em um mapeamento feito em 2010, Cirello (2010) registrou 113 instituições dedicadas a este trabalho no país até aquele momento. $\mathrm{O}$ volume crescente dessas organizações, por sua vez, deu margem à consolidação de uma trama institucional que envolveu, empresas baseadas no princípio da chamada "responsabilidade social", as quais financiavam parte destes trabalhos (com base em certos benefícios fiscais garantidos por subsídios públicos), além de toda uma rede de festivais voltados principal ou exclusivamente a "moradores de favelas"e "periferias", como o Cinecufa (Festival da ONG Central Única de Favelas) e o Festival Visões Periféricas, no Rio de Janeiro, ou o Festival Cine Favela, em São Paulo. Para mais detalhes sobre esta discussão, ver: Aderaldo (2016; 2017) 
Todavia, meu interesse em investigar a rede CVP deu-se na medida em que pude constatar que a mesma havia nascido como uma espécie de desdobramento de um conflito responsável por colocar em lados opostos os jovens aprendizes que, conforme dito, vinham passando pelos cursos de formação audiovisual oferecidos pelas ONGs e essas próprias instituições.

Em linhas gerais, a principal controvérsia surgiu quando alguns dos jovens que haviam passado por essas experiências de formação - sobretudo àqueles com maior capital escolar ou histórico de engajamento em movimentos de luta popular - passaram a sentir a necessidade de adotar um distanciamento crítico em relação às instituições do chamado "terceiro setor", pelo fato de notarem que a linguagem administrativa, normalmente utilizada nesses ambientes institucionais, acabava reforçando certos estigmas sociais, ao invés de combatê-los.

Não raro, as regiões periféricas eram traduzidas nos termos dos "projetos sociais" das ONGs de maneira isolada, como se se tratassem de áreas geográficas fixas, marcadas por situações de "carência" e "vulnerabilidade"; sendo que suas populações, comumente, acabavam descomplexificadas e reduzidas à simples condição de "vítimas" à espera de ajuda. Igualmente, era comum que essas mesmas populações fossem representadas de maneira alegórica, como detentoras de uma especificidade cultural. O que viabilizava a capitalização dessa "diferença" no mercado cultural hegemônico, ao mesmo tempo em que fortalecia a ideia de que tais áreas e populações marginalizadas poderiam ser pensadas como uma espécie de "outro" da cidade

Estas representações e sua linguagem moral - bastante eficaz na busca de financiadores externos - tendiam, portanto, a fixar aqueles que eram percebidos como "público alvo" das ONGs num certo imobilismo político e geográfico, amarrando-os ao mesmo tempo numa espécie de "prisão identitária" (Agier, 2011 [2009]; 2013) relacionada a identificações rígidas e opacas como: "jovens de periferia” ou "jovens de projeto". Caracterizações que, amiúde, legitimavam processos de evidente subalternização e exploração laboral ${ }^{9}$.

Era o caso, por exemplo, de situações onde, após adquirirem uma certa expertise técnica no tocante à produção audiovisual, os jovens acabavam sendo subcontratados pelas ONGs, recebendo (quando recebiam) valores muito abaixo do mercado e sem nenhum tipo de registro profissional, para realizarem as campanhas institucionais dessas organizações, sendo que, posteriormente, as mesmas obtinham renome e reconhecimento, justamente por estarem dando as "oportunidades" aos “jovens da periferia”.

Tal lógica (de subalternização) assemelhava-se àquela que servia para vincular as marcas de determinadas empresas - que patrocinavam algumas oficinas de "educação audiovisual", buscando o selo de "empresas socialmente responsáveis" - à suposta "qualificação" desses jovens. Sobre isso, faço uso da reflexão de Daniel Fagundes, membro do coletivo Núcleo de Comunicação Alternativa $(\mathrm{NCA})^{10}$ e que também era um dos integrantes da rede do vídeo popular, quando, durante uma conversa a respeito de sua trajetória, este me disse as seguintes palavras:

8 Uso o tempo verbal no passado para me referir a um conflito que marcou, de maneira pontual, a relação entre meus interlocutores e as ONGs no momento específico da pesquisa. Todavia, é importante assinalar que muitos dos problemas aqui destacados, continuam ocorrendo.

9 Sobre processos de precarização laboral no campo da "economia da cultura" ou da chamada "economia criativa”, ver De Tommasi (2016).

10 Para mais informações, ver: http://ncanarede.blogspot.com.br (Acessado em 27/05/2016). 
Os caras, principalmente dessas oficinas [de vídeo], vieram com essa coisa de que todo mundo já falou de favela e agora eles estavam trazendo essa ideia de que dariam o direito de a gente falar. Mas eles vendem, sabe? Era isso, eles vendiam a oficina. Eles tinham a aquisição dos equipamentos e a gente tinha o olhar, que depois virava uma propaganda para as próprias instituições, não é? Eu era aquele menininho que vinha com o carimbo do Itaú, da Camargo Correia e eles iam carimbando porque depois a gente virava dado para as próprias propagandas dessas empresas, onde eles diziam [imita] "Olha, o Itaú apoia o jovem da quebrada que saiu com a câmera na mão” (Daniel Fagundes, Entrevista ao autor, grifos meus).

Assim, em grande medida, a decepção de jovens como Daniel se devia ao fato dos mesmos entenderem que, apesar de terem mais e melhores condições para produzirem "imagens" sobre a cidade e suas desigualdades isso, não necessariamente, implicaria em uma verdadeira ampliação das condições para a alteração de um "imaginário" que insistia em essencializar a noção de "periferia”. Algo que me foi revelado de forma particularmente elucidativa por Fernando Solidade, também integrante do coletivo NCA e membro da rede CVP, ao dizer que:

(...) esses grupos de vídeo popular de hoje, esses grupos que se intitulam como "grupos de periferia" surgem para desconstruir um discurso da mídia (...). A mídia não mostra negros, vamos mostrar só negros, eles falam que aqui [nas periferias] é só violência, vamos mostrar o lado bom. Essa atitude fazia a gente virar praticamente uns parasitas da mídia. Até que a gente se deu conta de que não pode ser parasita da mídia. A gente não pode só dizer o contrário do que estão dizendo porque isso é aceitar ser pautado por eles e não falar nada (...). Foi discutindo a questão sobre o imaginário e não as imagens que a gente começou a notar a importância da nossa produção [referência às produçôes audiovisuais dos coletivos vinculados ao CVP]. Foi a hora que a gente começou a ficar puto com as ONGs porque elas vinham com esse papinho bonitinho de que "os jovens agora fazem suas próprias imagens", "os jovens agora contam sua própria história”, como se alguma chave no processo histórico estivesse sendo mudada. Concordo que tem mudança, a vida é dinâmica, só que as ONGs se colocam muito como os protagonistas dessa cena. Esse discurso: "nós possibilitamos que os jovens da periferia pudessem contar sua história, estão vendo o que a gente fez?” começou a irritar. A gente começou a ficar muito decepcionados e nos questionar: mas que porcaria de imaginário a gente está mudando? (Fernando Solidade, entrevista ao autor, grifos meus).

Foi, portanto, esse sentimento de desamparo e de falta de representatividade pública que reforçou certos vínculos de solidariedade e, simultaneamente, encorajou jovens como Daniel e Fernando a se engajarem em torno de uma associação informal responsável por 1) conectar uma série de coletivos que, assim como o NCA (coletivo do qual faziam parte), vinham se dedicando à realização de vídeos independentes, politicamente comprometidos e que, ao mesmo tempo, demonstrava-se capaz de 2) aproximar, por meio do uso de ferramentas comunicativas, diversas regiões e populações marginalizadas que, a despeito de sua descontinuidade espacial, possuíam fortes vínculos simbólicos e políticos entre si.

Entre 2009 e 2011 a rede CVP foi contemplada por um financiamento público voltado ao fomento de iniciativas culturais desenvolvidas por grupos não hegemônicos ${ }^{11} \mathrm{e}$, com os recursos obtidos, a associação produziu várias ações das quais destaco as três mais importantes, que foram: 1) a elaboração de uma publicação semestral intitulada "Revista Vídeo Popular"; 2) a organização de pacotes de DVDs produzidos pelos membros da rede e separados por linhas temáticas, os quais eram gratuitamente distribuídos, juntamente com a revista, em albergues,

11 Refiro-me ao Programa para a Valorização às Iniciativas Culturais (VAI). Uma lei municipal (N 13.540) que se destaca por privilegiar o financiamento de atividades culturais produzidas por agrupamentos não formalizados juridicamente; o que significa que as verbas do programa são repassadas diretamente aos coletivos contemplados, sem a necessidade de intermediários (ONGs, empresas, etc.), através de um dos membros que se inscreve na condição de "proponente". O uso desses subsídios, que, posteriormente, devem constar em uma prestação de contas ao município, pode ser alocado de muitas maneiras, como na aquisição de equipamentos comprovadamente essenciais para a execução do projeto. Mais informações em: http://programavai.blogspot.com.br (Acessado em 27/02/2016). 
escolas públicas, bibliotecas comunitárias, associações de bairro, universidades, sedes de movimentos sociais, entre outros lugares e 3) a estruturação de um circuito de exibição e debate de filmes em áreas marginalizadas da capital paulista.

Durante três anos, o acompanhamento etnográfico desta rede - frequentando suas reuniões e eventos, participando de suas listas de discussão na internet e acompanhando, de modo mais detido, as atividades de alguns dos coletivos que a integravam -, permitiu-me perceber que o esforço por construírem "pontes comunicativas" que fossem capazes de interligar uma série de áreas e populações marcadas por intensos processos de precarização sócio urbana em São Paulo trazia, para além do desejo de promover uma interlocução mais alargada entre essas populações, também um enorme conjunto de conhecimentos sobre as causas por trás da arquitetura opressiva da metrópole. Algo que, por sua vez, os incitava na direção de uma busca por ressignificar a própria noção de "periferia" e, consequentemente, a própria ideia de "cidade". Isso porque, na acepção desses agentes, o termo "periferia" não poderia ser resumido aos limites de ambientes geográficos fixos, posto que se trata de uma palavra que, na verdade, apenas nomeia um processo que vai além dos limites da materialidade dos espaços normalmente designados como "periféricos"12.

Da forma como a maior parte dos interlocutores ligados ao CVP pensavam, portanto, mais do que um ambiente geográfico fixo e homogêneo, a "periferia" deveria ser caracterizada como uma experiência social urbana definida por um tipo de mobilidade decorrente do acesso desigual a direitos. Em outras palavras, nos termos utilizados pela maior parte dos integrantes da rede CVP, a "periferia" era interpretada como uma "experiência" e, justamente por esse motivo, se referia a algo móvel, passível de ocupar o "centro" e as "margens", dada sua dinâmica itinerante. Assim, falar em "periferia", na perspectiva destes atores, necessariamente implicava em discutir o próprio modelo urbanístico hegemônico e suas dinâmicas (desiguais) de gestão sócio espaciais.

Deste modo, ao contrário de investir esforços no sentido de gerar comunicação entre os termos ("centro" e "periferia") demarcados por uma fronteira supostamente fixa e estável, o interesse dos atores vinculados à rede CVP caracterizava-se pela tentativa de utilizar a linguagem audiovisual como um modo de questionar as forças que produzem e administram as hierarquias responsáveis pela manutenção e pelo controle desses espaços liminares. Posição que, em grande medida, converge com aquela partilhada pelo segundo caso, a ser examinado no tópico seguinte, relacionado à experiência do coletivo carioca Projetação, cujas ações venho acompanhando no âmbito de uma investigação de pós-doutorado em curso.

\section{Coletivo Projetação}

Formado durante os eventos que ficaram conhecidos no Brasil como "jornadas de junho", no ano de $2013^{13}$ e dispondo da colaboração de mais de uma dezena de moradores de diferentes áreas do Rio de Janeiro, com níveis de formação, profissões, idades e perfis socioeconômicos

12 Detalhes sobre os conflitos vinculados às distintas maneiras de compreender e representar o termo "periferia" entre os atores vinculados à rede do Vídeo Popular podem ser vistos em Aderaldo (2016; 2017).

13 Sobre essas manifestações, que pararam as ruas do país durante vários dias, no mês de junho de 2013, já há um considerável acúmulo de bibliografia. Todavia, vale destacar que um interessante artigo sobre o modo como fer- 
muito heterogêneos, o Projetação caracteriza-se, principalmente, pelo uso de dispositivos tecnológicos como notebooks, caixas de som e projetores, com a finalidade de fazerem grandes projeções contendo mensagens de cunho político em diferentes suportes físicos (prédios, veículos, fachadas de instituições, praças), principalmente na capital carioca e municípios adjacentes.

Seus integrantes também costumam promover atos, debates e exibições de filmes dedicados a temáticas políticas em praças públicas, com o objetivo de trazerem à visibilidade o modo como uma série de problemas que afetam, de maneira muito direta, a vida da população encontram-se relacionados com mecanismos de produção de um modelo urbanístico acentuadamente individualista e excludente.

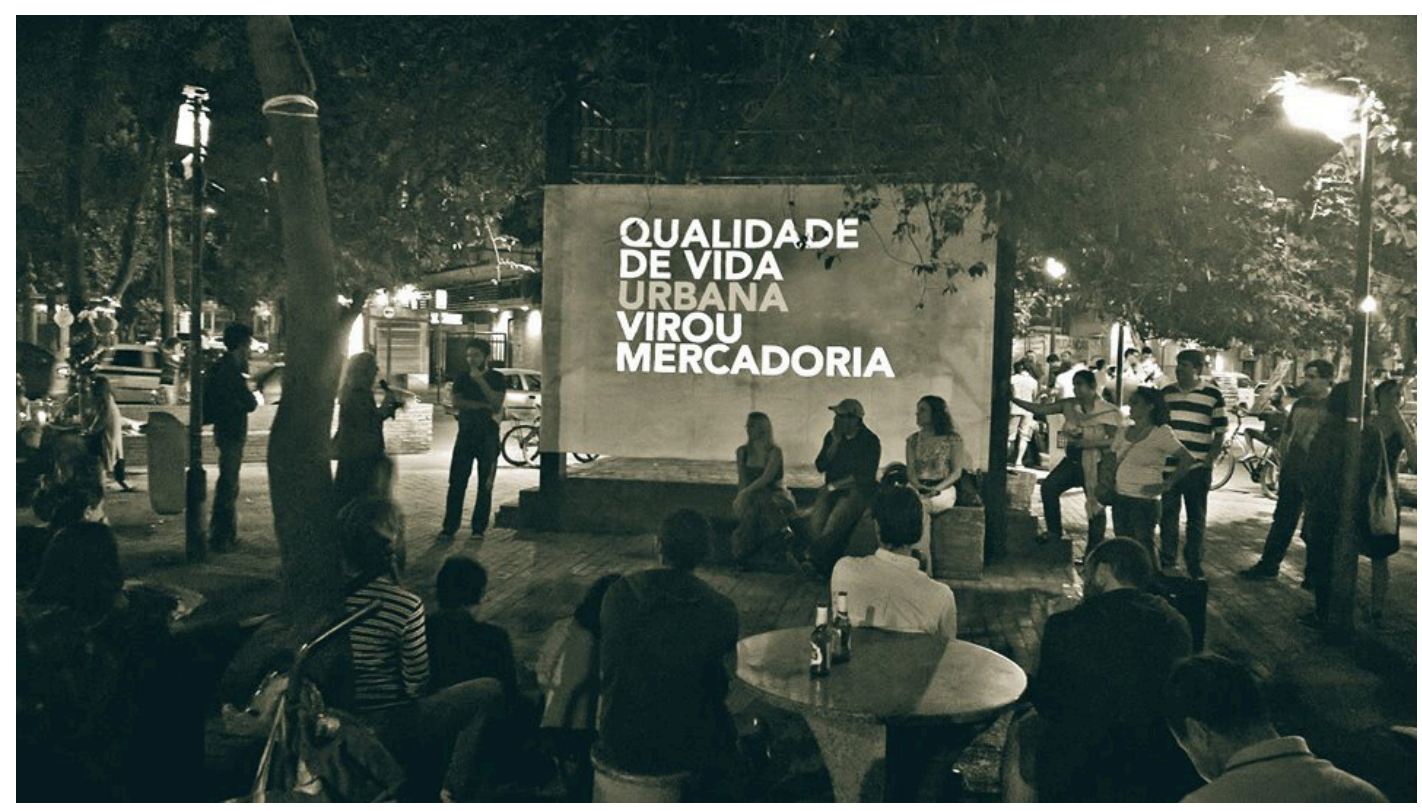

Debate sobre o filme "À queima roupa", que discute violência policial, na Praça São Salvador (Laranjeiras/Rio de Janeiro), organizada pelo Coletivo Projetação (Créditos: Guilhermo Aderaldo).

Contando com mais de vinte e sete mil seguidores em sua página na rede social Facebook, o coletivo arrecadou, por meio de uma campanha de Crowdfunding em $2014^{14}$, o equivalente a vinte mil reais. Valores que foram destinados à compra de uma série de equipamentos como caixas de som com tecnologia bluetooth (sem fios), projetores, computadores, gerador de energia e uma bicicleta adaptada para o transporte desses equipamentos.

A observação etnográfica de algumas das práticas do Projetação, desde o início de 2015, tem me permitido, entre outras coisas, compreender a importância adquirida pelo uso das novas tecnologias comunicativas no tocante à produção de um dinamismo social que decorre da capacidade que certos coletivos possuem para amarrar distintas redes e núcleos de ativismo urbano aparentemente fragmentados.

ramentas tecnológicas e comunicativas foram usadas nas supracitadas mobilizações, foi publicado por Hamburger (2016).

14 O vídeo da campanha, produzido pelos integrantes do coletivo, pode ser visto no seguinte endereço: https:// www.youtube.com/watch?v=E_0D1SaolyA (Acessado em 27/11/2016). 
Em certa ocasião, por exemplo, acompanhei o coletivo durante um ato crítico a uma universidade particular, localizada na região de Bonsucesso, no subúrbio do Rio de Janeiro, a qual havia se manifestado, durante uma reunião na secretaria municipal de transportes, contra a construção de uma ciclovia nos arredores do campus, sob alegação de que os alunos deixariam de ter lugar para estacionarem seus automóveis particulares.

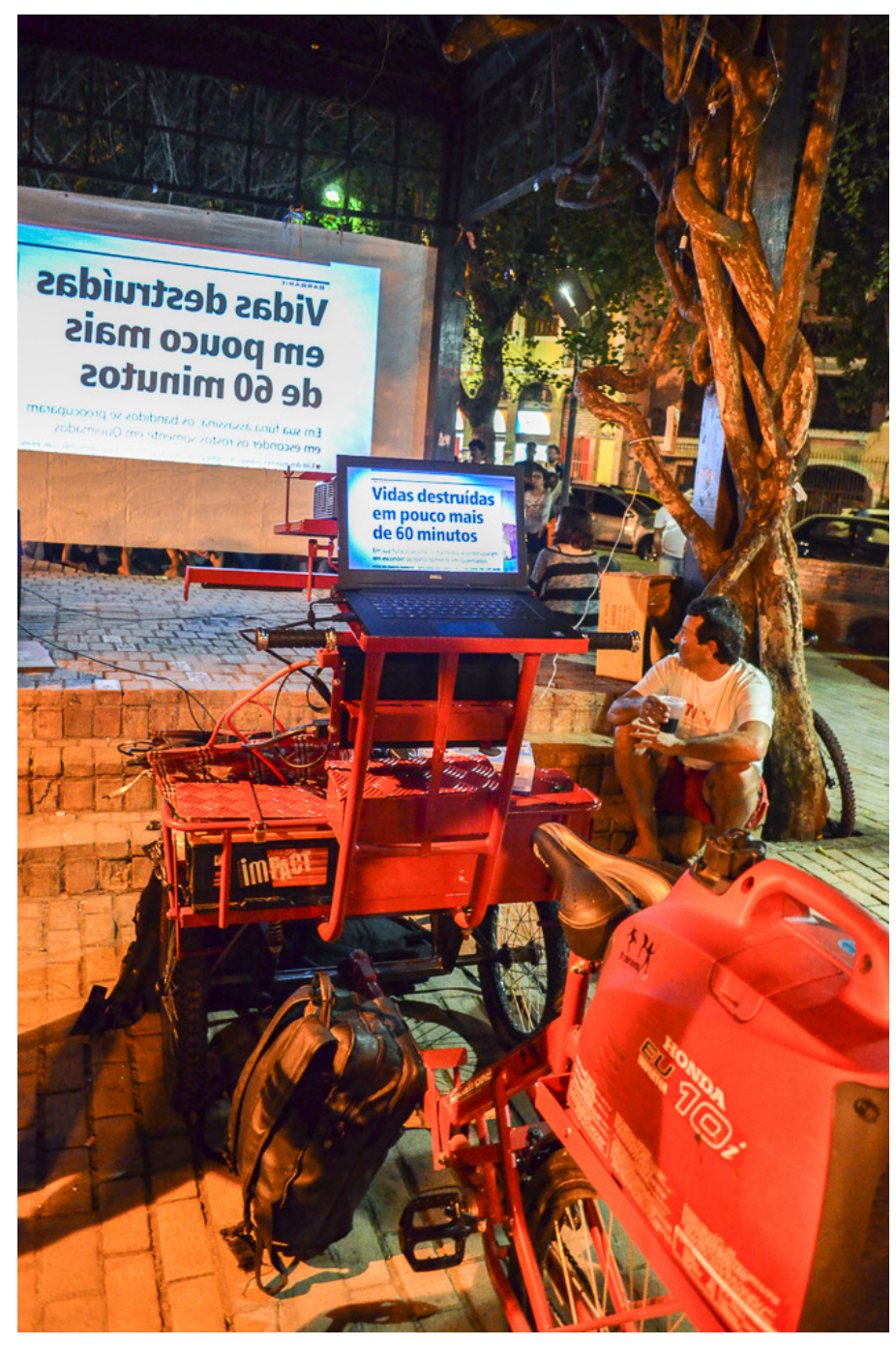

Bicicleta adaptada, Coletivo Projetação (Créditos: Guilhermo Aderaldo).

Para a referida ação, além de mim, compareceram à sede da universidade apenas quatro pessoas, sendo que, somente uma delas era mais diretamente relacionada ao Projetação. Apesar disso, a postagem das fotografias com as projeções em redes sociais voltadas à disseminação viral de conteúdo, somada ao uso de hashtags marcando redes de ciclo ativistas, coletivos de mídia, jornalistas politicamente engajados na causa da mobilidade urbana e defensores de direitos humanos, fez as imagens dispararem por diversos caminhos, gerando assunto para blogs e outras postagens.

No dia seguinte, em outra reunião na secretaria de transportes, a universidade voltou atrás e se posicionou a favor da construção da ciclovia. Apesar de não ter sido possível saber até que 
ponto a atuação do Projetação impactou esta mudança de posição por parte da instituição, fato é que o caso evidenciou o modo como as redes on e offline são utilizadas por tais interlocutores.

O acompanhamento deste tipo de intervenção, mobilizada por coletivos como o Projetação, portanto, se mostra importante na medida em que tais práticas são capazes de notabilizar uma diversidade de embates simbólicos e políticos localizados em torno das diferentes formas de interpretar e traduzir os sentidos por traz da topografia (e arquitetura) excludente que caracterizam a atual paisagem do Rio de Janeiro.

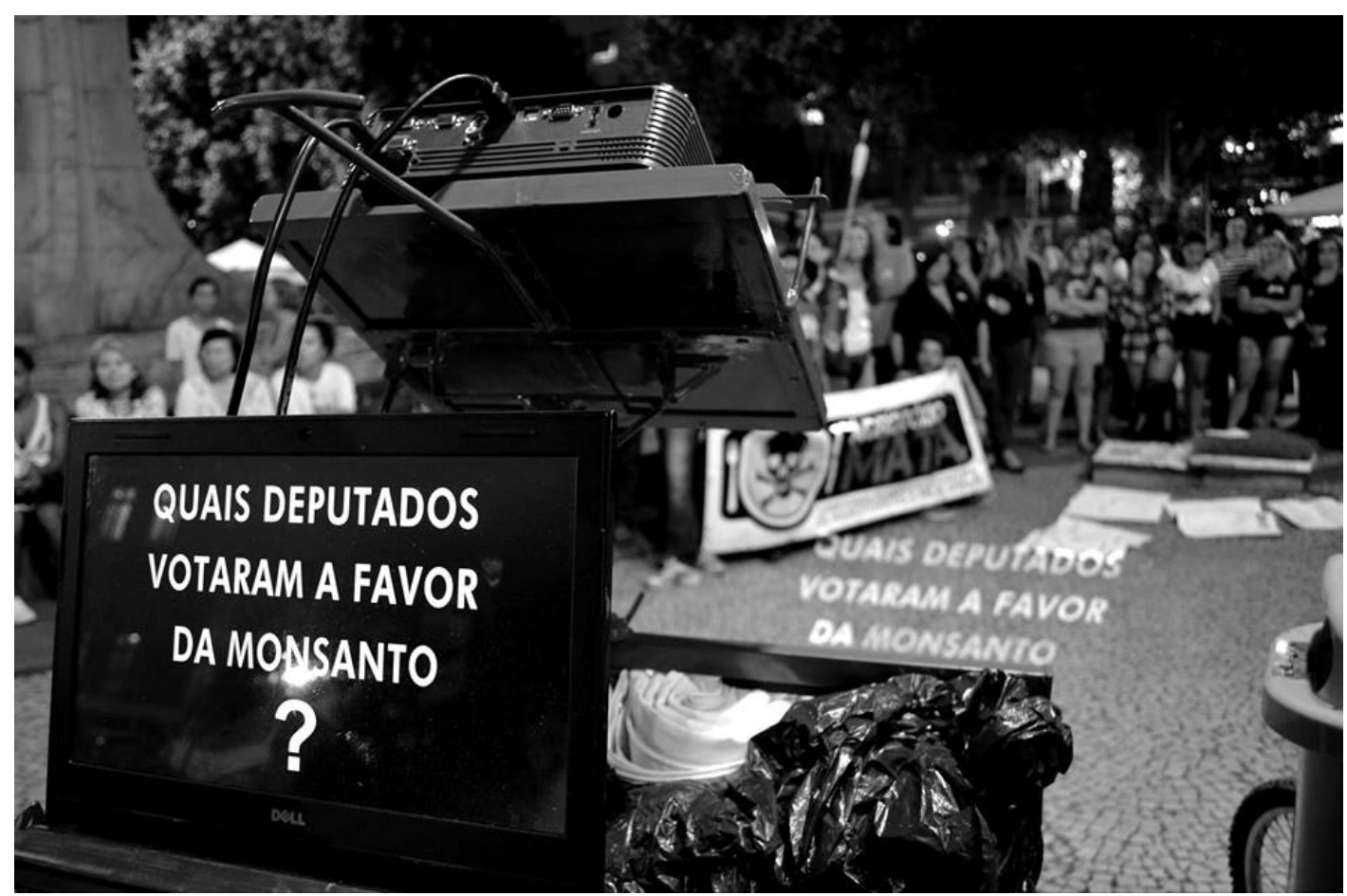

Protesto contra a Monsanto (Créditos: Guilhermo Aderaldo).

Num contexto marcado pela preparação de um ambiente urbano voltado a receber dois megaeventos esportivos globais (Copa do Mundo e Olimpíadas), as sucessivas gestões políticas responsáveis pela administração municipal da capital carioca vêm recrudescendo cada vez mais os modos de tratar as populações das favelas e áreas periféricas, tentando investir na imagem de uma "cidade pacificada", unida em torno do combate à violência ${ }^{15}$.

Desta forma, muitos esforços e recursos tem se voltado a uma tentativa de fortalecer fronteiras, através da construção de muros, sistemas de controle e vigilância eletrônica, além de outras barreiras menos visíveis mas igualmente "eficazes" como, por exemplo, a interrupção de certas linhas de ônibus que, até bem pouco tempo, ligavam as áreas mais pobres, nas zonas norte

15 Sobre as políticas destinadas à chamada "pacificação urbana” e seus desdobramentos, ver, por exemplo, Haesbaert (2014); De Tommasi e Velazco (2013); Telles (2015) e Graham (2016). Ver também um recente dossiê sobre o tema "Pacifications urbaines", publicado pela revista francesa L'Homme (2016), cujo sumário pode ser consultado no seguinte endereço: https://www.cairn.info/revue-1-homme-2016-3.htm (Acessado em 29/11/2016). 
e oeste da cidade às regiões mais abastadas, concentradas na área sul, visando delimitar o campo de circulação das populações menos privilegiadas ${ }^{16}$.

Tal contenção, por sua vez, tem sido significativamente legitimada por parte da imprensa e de certos extratos da população, como bem mostrou o geógrafo Rogério Haesbaert numa recente pesquisa, na qual o autor fez um recorte onde, no período de um ano, comparou o modo pelo qual os dois jornais impressos de maior circulação e voltados a distintos públicos, no Rio de Janeiro, cobriram os conflitos sociais nas favelas da cidade, com base em representações geográficas específicas.

Uma das constatações às quais foi possível chegar com a análise do material consultado por Haesbaert (2014), foi o fato de que a "cobertura geográfica" em um e outro caso variava consideravelmente, de acordo com o público para o qual cada diário estava direcionado. $\mathrm{O}$ jornal $\mathrm{O}$ Globo, por exemplo, prioriza claramente as notícias e conflitos ocorridos nas favelas da zona sul e do centro da cidade (áreas, reconhecidamente, mais privilegiadas), onde se localiza a maior parte de seu público leitor. Já O Dia, periódico voltado a um público de perfil mais "popular", caracteriza-se por uma cobertura mais abrangente das ações ocorridas nas favelas da cidade.

Ao se direcionarem a públicos de classes sociais distintas e que tendem a se concentrar em áreas diferentes do município, portanto, os jornais analisados acabam elaborando duas representações cartográficas visivelmente distintas do espaço urbano carioca ${ }^{17}$. Desta forma, como conclui o autor:

(...) ao ocultar uma parte expressiva da vida metropolitana, a mídia hegemônica acaba por estimular uma visão do urbano segmentada, privilegiando certos espaços e negligenciando outros, como se fosse promovida uma contenção que invisibiliza simbolicamente e contribui para depreciar ainda mais as áreas mais pobres da cidade (...). O Globo, ao invisibilizar ou minimizar as ocorrências em boa parte do espaço urbano, pode trazer também sérias implicações no direcionamento das políticas públicas. Enquanto principal jornal diário formador de opinião no Rio de Janeiro - especialmente em relação às classes mais favorecidas e influentes - ele de alguma forma direciona o olhar do Estado para aquilo que, midiaticamente, é produzido e veiculado como sendo a informação, o problema e/ou o espaço mais relevante da cidade. Se a representação das questões básicas privilegia ou aparece vinculada apenas a algumas áreas, é para elas, "naturalmente", que se dirigirá, de forma prioritária, a ação do Estado (Haesbaert, 2014: 265).

São, por conseguinte, essas representações hegemônicas sobre os espaços urbanos e os efeitos de poder que se desdobram de sua aceitação por parte, principalmente, dos setores médios e altos da população carioca, que se tornam a principal matéria prima para as intervenções produzidas pelo Projetação e também por outros coletivos e atores com os quais estes mantêm relações de afinidade ${ }^{18}$.

16 Ver, por exemplo: http://odia.ig.com.br/noticia/rio-de-janeiro/2015-09-20/mudancas-nos-onibus-irritam-moradores-da-zona-norte.html (Acessado em 02/05/2017)

17 No texto, Haesbaert (2014: 263), inclusive, produz dois mapas que corresponderiam às cartografias relacionadas à cobertura que cada um dos diários faz dos conflitos urbanos na cidade.

18 Alguns outros exemplos de coletivos e atores que vem se destacando pelo modo como se valem de recursos visuais com o objetivo de interpelarem a paisagem segregada da cidade são o coletivo Mariachi, o qual se dedica a práticas de produção de mídia alternativa, assim como os artistas visuais Alex Frechette e "Tavarez Vandal” (pseudônimo adotado pelo autor, cuja verdadeira identidade não é revelada publicamente pelo mesmo). Estes últimos se caracterizam por produzirem distintas intervenções estéticas/políticas pelos mais variados espaços do Rio e outras metrópoles. Além deles, cabe destacar a rede de coletivos e movimentos sociais intitulada "O Rio de Janeiro dos Jogos da Exclusão" a qual se dedicou a produzir uma série de ações e intervenções voltadas a denunciar o modelo elitista de cidade no qual se baseou o projeto do Rio de Janeiro como "Cidade Olímpica". A referida rede chegou, 
Deste modo, é possível dizer que a presença em algumas das atividades performativas organizadas pelo coletivo, em distintas situações, parece, de certa forma, confirmar a reflexão tecida por Vera Pallamin quando esta autora, a partir de um diálogo com a obra do filósofo franco-argelino Jacques Rancière, coloca o seguinte argumento:

(...) a performance enquanto uma maneira de produção de cultura urbana pode ser também um meio eficaz pelo qual embates "simbólicos" são veiculados, concretizados ou postos à prova no espaço público. Suas linguagens ampliam as possibilidades e meios estéticos de verificação das "partilhas do sensível" e do que estas significam no plano do político. Esta verificação ao mesmo tempo estética e política tem por base a observação do princípio da igualdade e sua presença nas formas de sociabilidade, permitindo, ou não, a participação naquilo que é "comum". Os movimentos dissensuais que enfrentam a atualização deste princípio são aqueles que configuram o motor do político, rearticulando formas de ação e percepção preestabelecidas (Pallamin, 2015: 158).

É o que acontece quando, para trazer alguns outros exemplos, o coletivo Projetação decide projetar sobre um prédio caracterizado pela residência de populações de camadas médias e altas, na zona sul do Rio de Janeiro, uma mensagem com os dizeres: "A PM mata pobre todo dia", seguida por uma animação que vai listando os nomes de uma série de moradores de favelas que haviam sido mortos por ações repressivas da polícia militar da cidade ${ }^{19}$.

Também podemos perceber essa tentativa de "verificação" do princípio de igualdade na produção e regulação dos espaços urbanos quando o mesmo coletivo projeta sobre uma viatura policial a frase: "Todo favelado é um perseguido político", como é possível ver entre as imagens presentes na página mantida pelo grupo na rede social Facebook ${ }^{20}$.

Algo da mesma natureza "dissidente" pode ser, igualmente, percebido quando refletimos sobre o terceiro e último caso a ser analisado neste artigo. Refiro-me ao projeto Cartograffiti, promovido por integrantes do coletivo paulistano Imargem.

\section{Cartograffiti e o Coletivo Imargem}

Banhada pela represa Billings e conhecida pelo fato de ser uma das áreas mais populosas e "pobres" de São Paulo - figurando entre os dez piores índices de desenvolvimento humano (IDH) da capital paulista ${ }^{21}$-, a região do Grajaú também se destaca no roteiro da chamada "arte urbana" da metrópole pois, dali saíram alguns dos artistas visuais mais conhecidos do país. Nos

inclusive, a produzir um mapa, no qual denuncia uma série de irregularidades, legitimadas pelas autoridades oficiais. Tal representação cartográfica do "Rio Olímpico", pode ser acessada através do seguinte endereço eletrônico: https://medium.com/@jogosdaexclusao/o-rio-de-janeiro-dos-jogos-da-exclus\%C3\%A3o-104624e70\#.5dx9yu7rw (Acesso em 26/02/2017).

19 Um vídeo desta ação, produzido e postado pelos integrantes do Coletivo Projetacão, pode ser visto em: https://www.facebook.com/plataformaprojetacao/videos/639392196114731/ (Acessado em 26/11/2016).

20 A supracitada imagem pode ser vista a partir do seguinte endereço: https://www.facebook.com/plataformaprojetacao/photos/a.517505761636709.1073741826.516672891719996/773369602716989/?type $=3 \&$ theater (Acessado em 26/02/2017).

21 Ver: http://fotos.estadao.com.br/galerias/cidades,idh-os-20-melhores-e-os-20-piores-distritos-de-sao-paulo,24925 (Acessado em 27/11/2016). 
muros do distrito podem ser encontrados graffitis de artistas de expressão nacional e internacional, como Alexandre Orion, Enivo, Paulo Ito, Mauro Néri, entre outros ${ }^{22}$.

Do Grajaú também surgiram músicos importantes do atual cenário fonográfico brasileiro, como o rapper Criolo. E foi ali, na mesma região, que nasceu o coletivo Imargem, formado inicialmente pelos irmãos Mauro e Wellington Néri. Dois artistas visuais e arte educadores locais ${ }^{23}$.

O Imargem costuma ser descrito por seus idealizadores como um "movimento" e têm como uma de suas principais propostas, a realização de ações estéticas que sejam capazes de colocar a rigidez do binômio centro/periferia sob perspectiva crítica, criando, desta forma, uma paisagem relacional da cidade. Nesta parte, abordarei uma das intervenções visuais produzidas por alguns dos integrantes deste coletivo, chamada Cartograffiti ${ }^{24}$.

Entre os anos de 2012 e 2015, o projeto Cartograffiti - viabilizado pela conquista de um financiamento público obtido junto à Secretaria de Cultura do município de São Paulo ${ }^{25}$ - teve como objetivo conectar simbolicamente as áreas localizadas no extremo sul da cidade, particularmente, o "Grajaú", ao "centro" da vida política, social e cultural da urbe paulistana.

Tratou-se de 21 intervenções de graffiti, realizadas por diferentes artistas urbanos convidados por Mauro Néri, as quais se localizariam em pontos estratégicos que, posteriormente, se transformariam em referências (pontos) para o trajeto de um ônibus aberto ao público.

A proposta do projeto, em síntese, foi a de produzir uma percepção itinerante/relacional do espaço urbano, que fosse capaz de estimular os visitantes a um tipo de experiência sensorial responsável por fazê-los, a partir do contato com as obras (graffitis), enxergar e perspectivar criticamente a própria cidade, assim como a rigidez das noções de "centro" e "periferia".

Ocorre que, apesar de estarem sendo financiados com recursos obtidos junto a um edital promovido pela Secretaria de Cultura do município, durante a execução das intervenções, paradoxalmente, muitos dos graffitis realizados no contexto do projeto foram, seguidas vezes,

22 Ver: http://www.brasilpost.com.br/2015/08/17/grafite-pichacao-grajau_n_8001398.html (Acessado em 27/11/2016).

23 Vale mencionar que Mauro Néri formou-se em artes plásticas no Brasil e, posteriormente, reforçou seus estudos na Itália. País onde viveu por um tempo em decorrência de um relacionamento com uma ex-companheira italiana. Embora criado pelos irmãos Wellington e Mauro Néri, após o retorno deste ultimo da Europa, o Imargem congrega uma rede de colaboradores esporádicos, oriundos de diversas regiões e com variadas trajetórias, origens sociais e níveis de formação. Os mesmos são chamados de "agentes marginais" nos termos do coletivo e se organizam, eventualmente, com o propósito de realizarem intervenções colaborativas em múltiplas regiões da cidade de São Paulo. O coletivo também protagonizou um dos episódios de uma série de filmes intitulada "Rua", realizada pela cineasta Tata Amaral. Outras informações sobre o coletivo Imargem podem ser obtidas diretamente no site do grupo, em: http://imagemdamargem.blogspot.com.br (Acessado em 27/05/2016). Já sobre a participação dos mesmos na série "Rua", é possível assistir ao vídeo completo em: https://www.youtube.com/watch?v=MPpyix3kQtw (Acessado em 27/11/2016).

24 Ver: http://projetocartograffiti.blogspot.com.br (Acessado em 27/11/2016).

25 Refiro-me aqui ao edital "Arte na Cidade", cujas informações detalhadas podem ser consultadas no seguinte site: http://www.prefeitura.sp.gov.br/cidade/secretarias/cultura/noticias/?p=7835_(Acessado em 27/11/2016). 
apagados por funcionários terceirizados do setor de limpeza urbana da mesma prefeitura que os havia subsidiado ${ }^{26}$.

Isto, por sua vez, ao invés de simplesmente dar espaço à reclamação dos artistas junto ao poder público, gerou uma verdadeira disputa narrativa e visual em distintas partes da cidade, na medida em que os mesmos passaram a integrar os apagamentos, chamados por eles de "apagões”, à própria “obra”.

Pouco a pouco, os graffitis que iam sendo apagados pela tinta cinza utilizada pelos funcionários da prefeitura, foram dando lugar a frases como "Prefeitura paga e apaga", "Apagaram a arte da cidade" ou, simplesmente, "Apagaram"27.

As frases, então, tornavam-se pontos do itinerário do ônibus vinculado ao projeto, tal qual ocorreria com os graffitis que deveriam figurar em seus lugares e, por meio delas, os artistas acabaram evidenciando a existência de tendências conflituosas envolvendo princípios e percepções distintos (e divergentes) em relação à representação (e às formas de gestão espacial) da "cidade" dentro do próprio poder público.

Se, por um lado, a secretaria de cultura parecia apostar numa ideia de espaço público caracterizada pela percepção positiva do conflito entre formas estéticas e políticas variadas, por outro, outros setores da mesma prefeitura não pareciam partilhar da mesma posição, buscando uniformizar a paisagem urbana, sobretudo, nas áreas mais centrais e com maior visibilidade.

Em 2015, um tempo após ter sido finalizada, a série de intervenções acabou se desdobrando num documentário ${ }^{28}$ e numa exposição realizada no Centro Cultural São Paulo (CCSP) ${ }^{29}$, além de ter alimentado uma variedade de debates relacionados ao tema do "direito à cidade", os quais foram organizados em distintas áreas da metrópole.

26 Cabe notabilizar o fato de que esses conflitos aumentaram consideravelmente no período atual, após o início da gestão do prefeito João Doria (PSDB), o qual implantou um programa de zeladoria urbana chamado "Cidade Linda" no qual declarou "guerra" às pichações e graffitis produzidos sem autorização. Com base neste mesmo programa, funcionários da prefeitura chegaram a apagar um enorme mural de graffitis na avenida 23 de maio, uma das principais vias da cidade, o qual havia sido financiado pela gestão anterior. Neste processo, Mauro Néri tornou-se uma espécie de símbolo da arbitrariedade do poder público para com os artistas de rua. Isso porque, durante a tentativa de apagar a tinta cinza que havia coberto uma de suas pinturas, a qual havia sido devidamente autorizada pelo poder público, o mesmo acabou sendo detido. O que mobilizou um enorme debate público a respeito do "incidente" envolvendo o artista. Para mais informações ver, por exemplo, a reportagem publicada no jornal Folha de São Paulo, no seguinte endereço: http://www1.folha.uol.com.br/cotidiano/2017/01/1853717-grafiteiro-e-detido-apos-escrever-em-muro-onde-teve-obra-apagada.shtml (Acessado em 26/02/2017). Todavia, também é válido notar que o mesmo Mauro Néri, após sua detenção, acabou recebendo o convite oficial da prefeitura de São Paulo, para integrar uma comissão de artistas com o objetivo de criar editais específicos de "arte urbana" para a capital. Sua aceitação do referido convite, por sua vez, abriu espaço para uma diversidade de debates e desentendimentos entre artistas da cidade. Os desdobramentos dessas disputas, porém, extrapolam os objetivos deste artigo.

27 Ainda sobre as praticas de apagamento de graffitis por parte de funcionários da prefeitura de São Paulo, recentemente, os diretores Marcelo Mesquita e Guilherme Valiengo, realizaram um documentário intitulado "Cidade Cinza”, cujo trailer pode ser visto no seguinte endereço: https://www.youtube.com/watch?v=7NpppZaGfJo (Acessado em 29/11/2016).

28 Ver: https://vimeo.com/141747076 (Acessado em 27/11/2016).

29 Um vídeo retratando os processos e sentidos por trás da referida exposição pode ser visto em: https://www. youtube.com/watch?v=5uelojF8GEE (Acessado em 26/02/2017). 


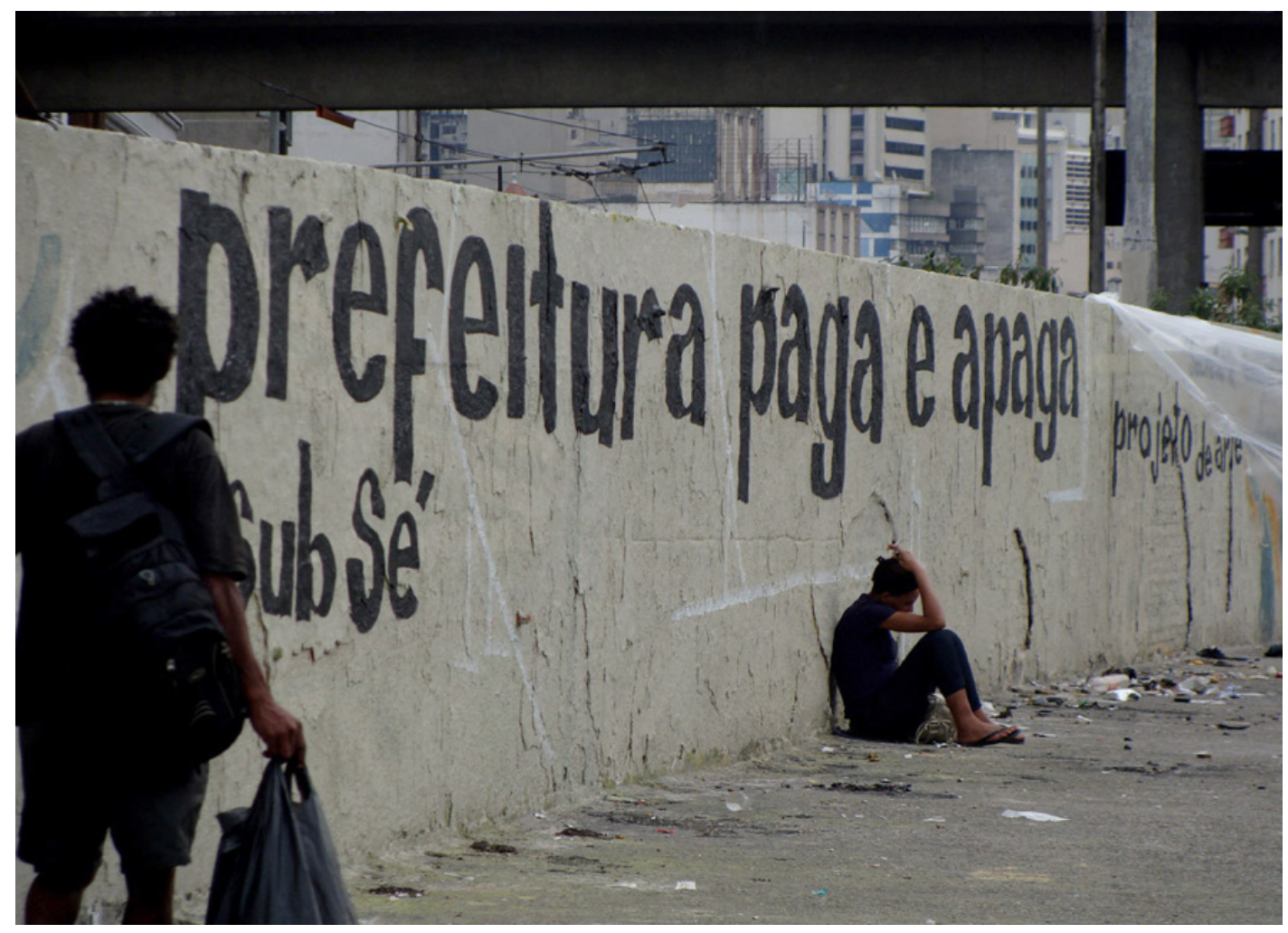

Frase escrita pelos integrantes do Imargem em muro "apagado" por agentes da prefeitura (Créditos: Mauro Néri).

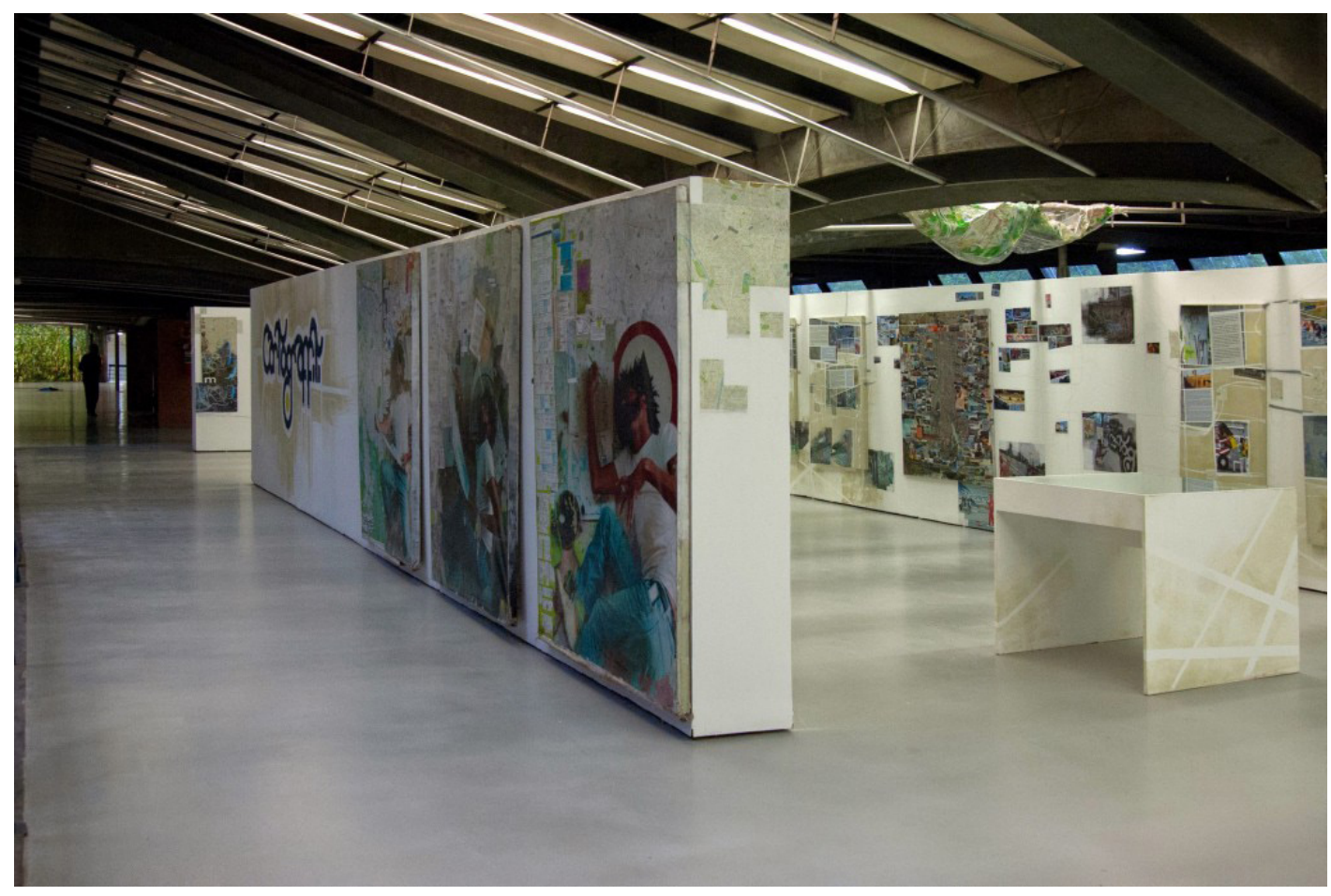

Exposição Cartograffiti, Centro Cultural São Paulo (Créditos: Guilhermo Aderaldo). 


\section{Algumas considerações finais}

O contato com parte da literatura acadêmica recente, cujos autores vêm se dedicando à investigação de fenômenos situados na fronteira que relaciona as dimensões da estética e da política, nos espaços urbanos, como é o caso de Campos (2011a; 2011b), Caldeira (2012), Pereira (2012; 2015), Raposo (2015), Aderaldo (2016; 2017), Castells (2013), Mesquita (2011; 2015), Di Giovanni (2015 a; 2015 b) e Pallamin (2015), por exemplo, nos ajuda a compreender o fato de que, nos últimos anos, interesses de natureza política têm, cada vez mais, se fundido com formas estéticas atreladas ao desejo de ocupar e ressignificar espaços, temporalidades e, ao mesmo tempo, alargar o alcance daquilo que é dizível/perceptível nas e sobre as cidades atuais.

Tais práticas e formas de associativismo, em vista disso, parecem evidenciar a emergência de novos campos para ações reivindicativas, alocados na confluência localizada entre, de um lado, o desgaste dos modelos tradicionais de engajamento e representação política (Mesquita, 2011; Castells, 2013; Pallamin, 2015; Di Giovanni 2015a; 2015b) e, de outro, a crise do chamado "campo artístico autônomo" (Canclini, 2012) ${ }^{30}$.

Foi buscando pistas para compreender algumas facetas desses processos, que me esforcei por aproximar os três exemplos de associativismo aqui reunidos, tomando como eixo central a forma pela qual os mesmos, apesar das suas diferenças, têm lançado mão de recursos visuais como meio de consolidar táticas de mobilização e engajamento nos espaços públicos urbanos. Busquei, assim, atribuir inteligibilidade à maneira como as formas de confrontação de referenciais normativos do espaço/tempo utilizadas nos três casos analisados, se assemelham quanto ao modo como manipulam "tática" (De Certeau, 1994 [1980]) e imaginariamente (Appadurai, 2005 [1996]) recursos estéticos/comunicacionais.

Ao promover esta justaposição de experiências, portanto, meu objetivo foi notabilizar a existência de regularidades entre elas, no tocante à efetuação de práticas que têm se revelado capazes de combinar os efeitos "desterritorializadores" relacionados à popularização das ferramentas tecnológicas - na medida em que as mesmas estimulam contatos não determinados pelos limites espaciais/geográficos -, com processos “reterritorializadores", que retomam as iniciativas de desenvolvimento de "referenciais simbólicos num espaço em movimento, no e pelo movimento" (Haesbaert, 2010: 279-280).

É justamente o que ocorre quando, por exemplo, o CVP, por meio do uso do vídeo, relaciona uma "ocupação" urbana, promovida por distintos movimentos de luta por moradia na região central de São Paulo e uma favela em alguma das pontas desta mesma metrópole, denominando como "periferia" a experiência de contiguidade política existente entre esses universos.

30 Para Canclini (2012), vivemos o momento da hegemonia de uma arte "pós-autônoma", ou seja, um referencial artístico mobilizado pela intersecção do sistema de arte junto a outros campos de enunciação. Nas palavras do autor o termo "arte pós-autônoma" busca definir "(...) o processo das ultimas décadas no qual aumentam os deslocamentos das práticas artísticas baseadas em objetos a práticas baseadas em contextos, até chegar a inserir as obras nos meios de comunicação, espaços urbanos, redes digitais e formas de participação social onde parece diluir-se a diferença estética" (Canclini, 2012:24). Ainda segundo Canclini (2012:24-25), "mais do que os esforços dos artistas ou dos críticos em romper a couraça, são as novas posições atribuídas ao que chamamos arte que estão arrancando-a de sua experiência paradoxal de encapsulação-transgressão". 
Semelhante efeito surge quando os integrantes do Projetação "desconectam" as imagens de moradores de favelas assassinados pela polícia militar carioca do registro direto de suas "comunidades" de origem e as inserem, através de enormes projeções, em fachadas de prédios reconhecidamente habitados pelas camadas médias e altas da cidade, em locais onde predomina o ordenamento urbano mantido pela lógica privada e individualista que alimenta o sistema segregador e punitivo, dominante na cidade.

Igualmente, o projeto Cartograffiti, na medida em que aposta no desenvolvimento de uma cartografia itinerante/relacional de São Paulo - modulada pela conexão entre os pontos ligados pelos graffitis (e também pelo registro de seus apagamentos) - elabora uma narrativa que compreende o território para além da dicotomia estanque centro/periferia. A intervenção visual produzida pelos integrantes do coletivo Imargem parece, assim, revelar a existência de uma cidade policêntrica, cuja visibilidade só se torna possível à medida em que nos abrimos para um tipo de experimentação espacial marcado por múltiplas perspectivas.

No fundo são as próprias fronteiras e seus mecanismos de regulação e controle, que parecem estar servindo de matéria-prima para as práticas criativas e insurgentes desses atores. Ao apostarem em intervenções que nos levam a refletir mais detidamente sobre a dimensão relacional dos territórios, os mesmos não apenas usam a cidade como painel/cenário para suas atividades "artísticas", mas também e, sobretudo, parecem estar se valendo dessas atividades com o propósito de abrir espaço para a reinvenção de outras formas de perceber e interpretar o que entendemos como "cidade". Mais ou menos à maneira do personagem Marco Pólo que, ao descrever a cidade imaginária de Olinda no famoso livro "As Cidades Invisíveis", do escritor italiano Ítalo Calvino, diz:

\footnotetext{
Quem vai a a Olinda com uma lente de aumento e procura com atenção pode encontrar em algum lugar um ponto não maior do que a cabeça de um alfinete que um pouco ampliado mostra em seu interior telhados, antenas clarabóias, jardins, tanques, faixas através das ruas, quiosques nas praças, pistas para as corridas de cavalos. Aquele ponto não permanece imóvel: depois de um ano, já está grande como um limão; depois, como um cogumelo; depois, como um prato de sopa. E eis que se torna uma cidade de tamanho natural, contida na primeira cidade: uma nova cidade que abre espaço em meio à primeira e impele-a para fora (...) (Calvino, 1972 [1990]: 119).
}

Logo, é possível dizer que tais práticas e representações, antes de qualquer coisa, revelam o desejo por um urbanismo que estimule o surgimento e conserve a existência de mundos plurais e não hierarquizados. Modelo utópico que incita à imaginação e leva a um movimento constante de busca por uma cidade que seja o lugar de todos os lugares.

\section{REFERÊNCIAS}

Aderaldo, Guilhermo. 2017. Reinventando a cidade: uma etnografia das lutas simbólicas entre coletivos culturais vídeo-ativistas nas "periferias" de São Paulo. São Paulo: Annablume/Fapesp. 2016. "Entre imagens e imaginários: estética e política nas intervenções visuais/audiovisuais de coletivos culturais paulistanos". pp. 55-79 em: Pluralidade urbana em São Paulo: vulnerabilidade, marginalidade, ativismos sociais. Organizado por Kowarick, Lúcio e Frúgoli Jr, Heitor. São Paulo: Editora 34.

Agier, Michel. 1999. L’invention de La ville. Paris: Archieves contemporaines. 
2011 [2009]. Antropologia da cidade: lugares, situaçôes, movimentos, São Paulo: Terceiro Nome.

2013. La condition cosmopolite: l'anthropologie à l'épreuve du piège identitaire. Paris: Éditions La Decouverte.

Appadurai, Arjun. 2005 [1996]. Après le colonialisme: les consequences culturelles de la globalisation. Paris: Petit Bibliotèque Payot.

Caldeira, Teresa Pires do Rio. 2012. "Inscrição e circulação: novas visibilidades e configurações do espaço público em São Paulo": Novos estudos - CEBRAP, São Paulo, No 94, pp. 31-67. Disponível em: <http://www.scielo.br/scielo.php?script=sci_arttext\&pi$\mathrm{d}=\mathrm{S} 010133002012000300002 \& \operatorname{lng}=\mathrm{en} \& \mathrm{nrm}=$ iso >

Calvino, Ítalo. 1972 [1990]. As cidades invisíveis, São Paulo: Cia das Letras.

Campos, Ricardo. 2011a. "Identidade, imagem e representação na metrópole” pp. 15-30. Em: Uma cidade de imagens. Produçóes e consumos visuais no meio urbano. Organizado por Campos, R; Andrea, B e Spinelli, L. Lisboa: Ed Mundos sociais.

. 2011b. "O direito à voz no espaço público. Uma reflexão em torno das formas de apropriação juvenil dos territórios urbanos”, pp 135-147. Em: Espaço público e direitos humanos: novos desafios, organizado por Martins, Rosana, Pedroso, Maria Goretti e Cádima, Francisco. Rio de Janeiro: Ed. Multifoco.

Canclini, Néstor Garcia. 2012. A sociedade sem relato: antropologia e estética da iminência. São Paulo: Ed. Edusp.

Canevacci, Massimo. 2004. A cidade polifônica: ensaio sobre a antropologia da comunicação urbana, São Paulo: Ed. Studio Nobel.

Castells, Manuel. 2013. Redes de indignação e esperança: movimentos sociais na era da internet, Rio de Janeiro: Zahar.

Cirello, Moira. 2010. Educação audiovisual popular no Brasil - Panorama 1990 - 2009. Tese de doutorado (Comunicações), Universidade de São Paulo.

De Certeau, Michel. 1994 [1980]. A invenção do cotidiano. Vol 1. Artes de fazer, Rio de Janeiro: Vozes.

De Tommasi, Lívia e Velazco, Daniela.2013. “A produção de um novo regime discursivo sobre as favelas cariocas e as muitas bases do empreendedorismo debase comunitária”. RevistaInstituto de Estudos Brasileiros, São Paulo, n 56,pp. 15-42,jun 2013.Disponível em: < http://www.scielo.br/scielo.php?script=sci_arttext\&pid=S0020-38742013000100002\&lng=en\&nrm=iso

De Tommasi, Lívia. 2016. "Culto da performance e performance da cultura: os produtores culturais periféricos e seus múltiplos agenciamentos". Revista Crítica e Sociedade, 5 (2). Disponível em: <http://www.seer.ufu.br/index.php/criticasociedade/article/view/34838>

Di Giovanni, Júlia Ruiz. 2015a. Cadernos do outro mundo: o Fórum Social Mundial em Porto Alegre. São Paulo: Ed. Humanitas/FAPESP.

.2015b. Artes de abrir espaço. Apontamentos para a análise de práticas em trânsito entre arte e ativismo. Cadernos de Arte e Antropologia, 4 (2) pp. 13-27. Disponível em: https:// cadernosaa.revues.org/911 D DOI:

10.4000/cadernosaa.911:

Feixa, Clarles e Nofre, Jordi (Eds). 2013. \#Generaciónindignada: topias y utopias del 15M. Lleida: Milenio.

Graham, Stephen. 2016. Cidades sitiadas: o novo urbanismo militar. São Paulo: Boitempo.

Haesbaert, Rogério. 2010. O mito da desterritorialização: do fim dos territórios à multiterritorialidade. Rio de Janeiro: Bertrand Brasil. 
. 2014. Viver no limite: território e multi/transterritorialidade em tempos de in-segurança e contenção. Rio de Janeiro: Ed. Bertrand Brasil.

Hamburger, Esther. 2016. "Saímos do Facebook?”, pp. 293-320. Em: Pluralidade urbana em São Paulo: vulnerabilidade, marginalidade, ativismos sociais. Organizado por Kowarick, Lúcio e Frúgoli Jr, Heitor. São Paulo: Editora 34.

Mesquita, André. 2011. Insurgências Poéticas: arte ativista e ação coletiva. São Paulo: Annablume. . 2015. Esperar não é saber: a arte entre o silêncio e a evidência. São Paulo. Ed. Do autor.

Pallamin, Vera. 2015. Arte, cultura e cidade: aspectos estético-politicos contemporâneos. São Paulo, Ed. Annablume.

Pereira, Alexandre Barbosa. 2012. "Quem não é visto, não é lembrado: sociabilidade, escrita, visibilidade e memória na São Paulo da pichação", Cadernos de Arte e Antropologia, 1 (2) pp. 55-69. Disponível em: https://cadernosaa.revues.org/631

. 2015. "Escritas dissonantes: escolarização, letramentos, novas tecnologias e práticas culturais juvenis”. Horizontes antropológicos, Porto Alegre, 21 (44), pp. 81-107. Disponível em: <http://www.scielo.br/scielo.php?script=sci_arttext\&pid=S010471832015000200081\&1$\mathrm{ng}=\mathrm{en} \& \mathrm{nnm}=\mathrm{iso}>$

Ponty, Merleau. 2014. O visivel e o invisível. São Paulo: Perspectiva.

Raposo, Paulo. "Artivismo": articulando dissidências, criando insurgências , In: Cadernos de Arte e Antropologia, 4 (2), pp. 3-12. Disponível em: https://cadernosaa.revues.org/909

Telles, Vera da Silva. 2015. Cidade: produção de espaços, formas de controle e conflitos, Revista de Ciências Sociais, Fortaleza, 46 (1), pp. 15-41. Disponível em: <http://www.rcs.ufc.br/ edicoes/v46n1/rcs_v46n1a1.pdf>

\title{
TeRRITORIES, MOBILITY, AND INSURGent AESTHETICS. RefLeCTING ON PRACTICES AND COLLECTIVE REPRESENTATIONS AMONGST VISUAL ARTIST IN CONTEMPORARY METROPOLISES
}

\begin{abstract}
Based on recent ethnographic research, this article revisits some fieldnotes on the popularization of the access to visual and/or audiovisual production tools that have encouraged new forms of associativism and political engagement in the contemporary Latin-American metropolises. More specifically, drawing upon three cases of "cultural activism" or "art activism "in the cities of São Paulo and Rio de Janeiro", led by precarious young workers involved in the so-called "creative professions", I aim to understand how these experiences challenge hegemonic logics that sustain deeply excluding urbanistic models.
\end{abstract}

Keywords: city, associativism, artistic-activist collectives, urban visual interventions, sociability

Recebido em: 2016-11-30

Aceitado em: 2017-04-25 